\title{
THERMAL AND MECHANICAL FATIGUE IN A QE22 MAGNESIUM ALLOY REINFORCED WITH SHORT SAFFIL FIBRES
}

Using non-destructive methods changes in the microstructure of QE22 metal matrix composites (MMC) due to thermal and mechanical cycling have been investigated. Thermal stresses induced in composites due to a considerable difference between thermal expansion coefficients of the matrix and ceramic reinforcement may create new dislocations on cooling from elevated to ambient temperature. Thermal stresses can achieve the yield stress of the matrix and micro-glide of newly created dislocations as well as their annihilation can occur. Thermodynamic processes in the matrix influence these effects.

Keywords: Metal matrix composites, Squeeze casting, Dislocations, Internal friction, Acoustic properties, Thermal properties

\section{Introduction}

Commercial magnesium alloy QE22 was derived from $\mathrm{Mg}$ RE-Zr alloys by the addition of silver, which improves mechanical properties of the alloy. Good creep resistance is attributed to both the strengthening effect of precipitates and the presence of the grain boundary phases that reduce the grain boundary sliding. Ageing causes precipitation within the grains. The precipitation process depends on silver content [1]. If the silver content is less than $2 \mathrm{wt} . \%$, the precipitation process appears to be similar to that occurring in Mg-RE alloys, i.e. it starts with the GP zones (Mg-Nd, coherent) and finishes with $\mathrm{Mg}_{12} \mathrm{Nd}$ incoherent precipitates. For higher amounts of silver two independent precipitation processes have been reported; both started with Mg-Nd GP zones, rod-like or ellipsoidal, and leading ultimately to the formation of an equilibrium phase of probable composition $\mathrm{Mg}_{12} \mathrm{Nd}_{2} \mathrm{Ag}$ [2]. A considerable improvement of the mechanical properties as well as the thermal stability of the alloy can be achieved by the reinforcement by ceramic fibres. Magnesium matrix composites possess good wear resistance, enhanced strength, good damping capacity and creep resistance and they keep low density and good machinability [3-5]. Benefits of the fibre reinforcement can be powered by precipitation hardening. Enhanced mechanical properties of commercial Mg-Ag-Nd-Zr alloy reinforced by short Saffil fibres have been reported elsewhere [3,6]. A difference between thermal expansion coefficients (CTEs) of the matrix and the reinforcement is a very important factor in composites with a metallic matrix. The coefficient of thermal expansion of a ceramic reinforcement is lower than that of most metallic matrices. This means that when a composite is subjected to temperature changes, thermal stresses arise at the interfaces between the matrix and the reinforcements. Thermal stresses resulting from a thermal mismatch can generally be expressed in the following form

$$
\sigma_{T S}=f\left(C, r_{i}\right) \Delta \alpha \Delta T \text {, }
$$

where $f\left(C, r_{i}\right)$ is a function of the elastic constants, $C$, and geometrical parameters $r_{i}, \Delta \alpha$ is the difference in value of the thermal expansion coefficient of the two components and $\Delta T$ is the temperature change. The thermal stresses may relax and new dislocations are generated in the matrix. Therefore, there is a higher dislocation density in the matrix, especially near the interfaces. This high matrix dislocation density as well as the reinforcement/matrix interfaces can provide a high diffusivity path in metal matrix composites (MMC). The higher dislocation density would also affect precipitation kinetics in a precipitation hardenable matrix.

The aim of the present paper is to investigate QE22 magnesium alloy reinforced with $\delta$ - $\mathrm{Al}_{2} \mathrm{O}_{3}$ (Saffil) submitted to thermal and mechanical loading and to determine possible physical and thermodynamic processes occurring in the matrix. Non-destructive methods are used in this study.

\section{Experimental procedures}

\subsection{Material}

Composites were prepared by squeeze casting. Commercial QE22 alloy (nominal composition 2.5 wt.\% Ag, 2 wt.\% Nd rich Rare Earth, $0.6 \mathrm{wt} . \% \mathrm{Zr}$, balance $\mathrm{Mg}$ ) was used as the matrix material. The alloy was reinforced with $\delta-\mathrm{Al}_{2} \mathrm{O}_{3}$ short fibres (Saffil ${ }^{\circledR}$ ) with a mean diameter of $3 \mu \mathrm{m}$ and a mean length about $87 \mu \mathrm{m}$ (measured after squeeze casting). The preforms consisting of the $\mathrm{Al}_{2} \mathrm{O}_{3}$ short fibres showing a planar isotropic fibre distribution and a binder system (containing $\mathrm{Al}_{2} \mathrm{O}_{3}$ and starch) were preheated to a temperature of $1000{ }^{\circ} \mathrm{C}$ that is higher than the temperature of the melt alloy and then inserted into a preheated die. The two-stage application of the pressure resulted in MMCs with a fibre volume fraction of 17.5 vol. \%. The pressure required to force the melt into the die with the preform was $50 \mathrm{MPa}$ for $30 \mathrm{~s}$ in the first step and 130 $\mathrm{MPa}$ for $90 \mathrm{~s}$ in the second step. The second step closes pores and

\footnotetext{
* Zuzanka Trojanová, Pavel Lukáč

Department of Metal Physics, Faculty of Mathematics and Physics, Charles University, Ke Karlovu 5, 12116 Praha 2, Czech Republic.

Tel.: +420 221911366; Fax +420 221911490; E-mail: ztrojan@met.mff.cuni.cz
} 
shrinkage cavities. The short time of contact between the liquid alloy and the fibres leads to only slight reactions between the fibres and the matrix.

\subsection{Damping measurements}

Damping measurements were carried out on bending beams ( $80 \mathrm{~mm}$ long with thickness of $3 \mathrm{~mm}$ ) in vacuum (about $30 \mathrm{~Pa}$ ) at ambient temperature. The damping was obtained by the measurement of the logarithmic decrement of free decaying bending beam vibrations in an apparatus described elsewhere [7]. The bending beams fixed at one end and a permanent magnet attached at the free end dipping into a coil system were contactlessly excited to mechanical resonance of their fundamental vibration (clampedfree-bar with end loading) by an alternating magnetic field. This was realised by a closed feedback loop consisting of an excitation coil, an induction coil and a power AC amplifier. The free decaying vibration was determined via the effective alternating voltage induced by the moving permanent magnet into the induction coil. After reaching a certain (required) amplitude, the coil current was switched off by a PC and the declining mechanical vibration was stored in the $\mathrm{PC}$ via an $\mathrm{ADC}$ measuring the voltage induced by the moving permanent magnet $[7,8]$. Using these data, the logarithmic decrement $\delta$ of the free vibration was determined by the PC according to exponential law

$$
A(t)=A_{0} \exp (-\delta t / \tau)
$$

In Eq.(2), $A_{0}$ is the required amplitude, $t$ is time and $\tau$ is the period of vibrations.

\subsection{Cycling of samples}

Fatigue was realised by the controlled bending loading of the bending beam samples in the same apparatus as used for the damping measurements controlling the amplitude and number of vibrations. The samples were cycled for a certain time at a predefined amplitude. From the time and resonant frequency, the number of cycles was calculated. Immediately after cycling, the strain amplitude dependence of the decrement was measured. The resonant frequency of the system ranged from 71 to $73 \mathrm{~Hz}$. The sample was cycled up to fracture, which was reached at $N=2.19 \times 10^{8}$ cycles.

\section{Experimental results and discussion}

\subsection{Thermal cycling}

For many metallic materials, the strain dependence of the damping capacity can be divided into a strain independent and a strain dependent component. In the case of the logarithmic decrement, this experimental finding can be written as:

$$
\delta=\delta_{0}+\delta_{H}(\epsilon)
$$

$\delta_{0}$ is the amplitude independent component, found at low amplitudes. The component $\delta_{H}$ depends on the strain amplitude $\epsilon$ and is usually caused by dislocation vibration in the material.

Figure 1a shows the plots of the logarithmic decrement against the logarithm of the strain amplitude for QE22+17.5vol.\% Saffil composite before and after thermal cycling between the room temperature and increasing upper temperature up to $320{ }^{\circ} \mathrm{C}$. Figure $1 \mathrm{~b}$ shows the plots obtained at higher upper temperatures $(320$, 360 and $400{ }^{\circ} \mathrm{C}$ ). From Figs. 1a and $1 \mathrm{~b}$, it can be seen that the strain dependences of the logarithmic decrement exhibit two regions in good accord with Eq. (3). The values of $\delta_{H}$ in the strain amplitude dependent region increase very strongly with increasing upper temperature of the cycle up to $360^{\circ} \mathrm{C}$ and then, above $360{ }^{\circ} \mathrm{C}$, the values of $\delta_{H}$ (at given strain amplitudes) decrease with the upper temperature. The critical strain $\epsilon_{c r}$ at which the logarithmic decrement becomes amplitude dependent may be used to calculate the effective critical stress amplitude corresponding to the micro-yield stress according to the equation

$$
\sigma_{c}=E \epsilon_{\mathrm{cr}}
$$

where $E$ is Young's modulus.

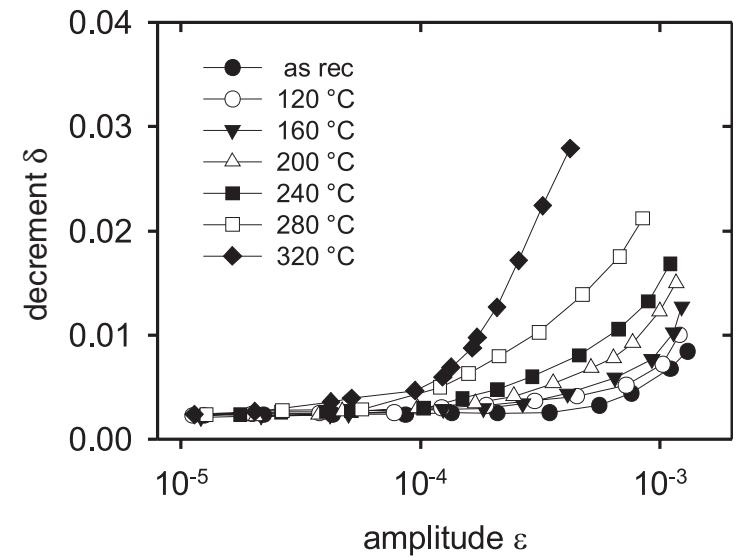

Fig. 1 (a) Amplitude dependence of decrement for QE22+17.5 vol.\% Saffil obtained after thermal cycling between room temperature and various upper temperatures (up to $320{ }^{\circ} \mathrm{C}$ ).

The experimental data indicate microstructure changes in specimens. An increase of internal stresses due to the difference in CTE is very probably responsible for these changes. The internal stresses produced by thermal loading of composites can be reduced by various relaxation mechanisms: creation of new dislocations and their glide, by decohesion or sliding of the matrix/reinforcement interface, by diffusion of solute atoms in the matrix. It is expected that the dislocation density near the reinforcements is significantly higher than that elsewhere inside of the matrix. The dislocations formed during cooling from an elevated temperature to a certain lower temperature can glide inducing plastic deformation in the matrix. An increase in the dislocation density near reinforcement fibres has been calculated as $[9,10]$ 


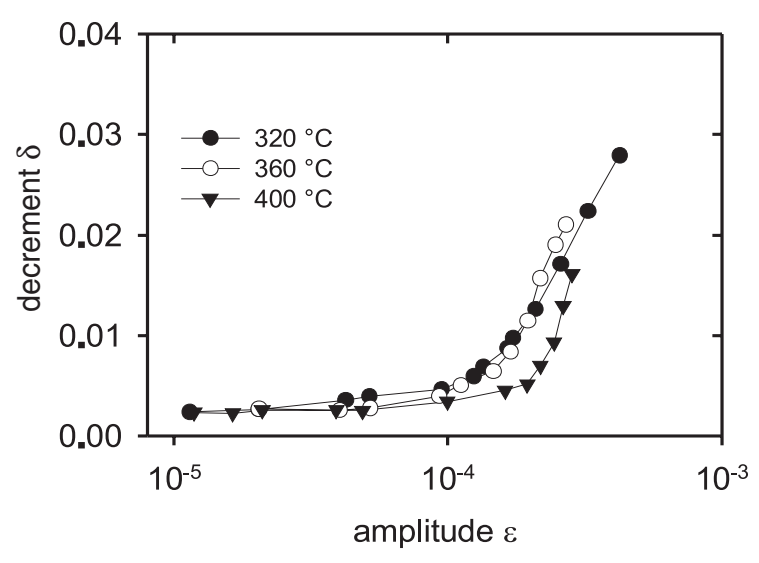

Fig. 1 (b) Amplitude dependence of decrement for QE22+17.5 vol.\% Saffil obtained after thermal cycling between room temperatures and upper temperatures 320,360 and $400{ }^{\circ} \mathrm{C}$.

$$
\Delta \rho=\frac{B f \Delta \alpha \Delta T}{b(1-f)} \frac{1}{d},
$$

where $f$ is the volume fraction of the reinforcing phase, $d$ is its minimum size, $b$ is the magnitude of the Burgers vector of dislocations and $B$ is a geometrical constant. From Eq. (5) it follows that the dislocation density increases as the temperature difference increases. The residual thermal stresses are developed within the matrix during cooling. As QE22 matrix becomes softer with temperature, the internal thermal stresses in the matrix can exceed the matrix yield stress. Then, new dislocations are formed, they can glide and the matrix deforms. Highly strained zones, plastic zones, are formed. The zones with higher dislocation density are adjacent to reinforcements.

The strain amplitude dependence of the logarithmic decrement suggests dislocation unpinning processes. The differences in the damping behaviour of specimens thermally cycled to various upper temperatures can be attributed to the interaction between dislocations and point defects (solute atoms) including small clusters of foreign atoms and to changes in the dislocation density.

The strong strain dependence of the logarithmic decrement for QE22/ $\mathrm{Al}_{2} \mathrm{O}_{3}$ composite specimens shown in Fig. 1 may be explained using the Granato-Luecke theory of the dislocation damping. In the Granato-Luecke theory [11, 12] the dislocation structure is assumed to consist of segments of $L_{N}$ length along which weak pinning points are randomly distributed. The mean distance between two weak pinning points is $\ell$, with $\ell \ll L_{N}$. The ends of the longer segments $L_{N}$ are assumed to be unbreakable (strong) pinning points. The mean total density of dislocations is $\rho$. The periodic stress $\sigma=\sigma_{0} \sin \omega t$ is applied. At $T=0$, the dislocation loop is able to breakaway from the weak pinning points only at a sufficiently high stress. The stress necessary for breakaway of dislocations is determined by the largest double loop in a segment and it is strongly dependent on the statistic distribution of the pinning points. With increasing temperature (for $T>0 \mathrm{~K}$ ), the stress is decreased because the breakaway process is thermally activated [13]. At higher temperatures the breakaway can occur at lower stresses than possible for double loop. However, higher activation energies are required because the breakaway is simultaneous from several neighbouring weak pinning points. At higher temperatures and low frequencies approximation, the stress dependence of the logarithmic decrement component $\delta_{H}$ can be expressed as [13]

$$
\begin{aligned}
& \delta_{H}=\frac{\rho L_{N}^{2}}{6} \frac{v}{\omega}\left(\frac{3 \pi k T}{2 U_{0}}\right)^{1 / 2}\left(\frac{\ell^{3} \sigma_{0}^{2}}{U_{0} G}\right)^{1 / 2} \\
& \exp \left[-\frac{4}{3} \frac{U_{0}}{k T}\left(\frac{U_{0} G}{\ell^{3}}\right)^{1 / 2} \frac{1}{\sigma_{0}}\right]
\end{aligned}
$$

where $G$ is the shear modulus, $\sigma_{0}$ is the amplitude of the applied stress and $\omega$ is its frequency, $v$ is the dislocation frequency, $U_{0}$ is the activation energy, $k$ is the Boltzmann constant. With increasing upper temperature of the thermal cycle the decrement component $\delta_{H}$ increases, too. The observed behaviour may be explained if we consider that (a) during cooling and also during thermal cycling, new dislocations are created due to the difference in the CTE and/or (b) new pinning points on existing dislocations may be formed by thermodynamic processes in the matrix that can modify the number of free foreign atoms or their small clusters. Kiehn et al. [14] investigated the microstructure of QE22 with 26 vol.\% Saffil fibres after the annealing step by step at increasing temperature using transmission electron microscopy. They observed incoherent matrix particles containing $\mathrm{Zr}, \mathrm{Nd}$ and $\mathrm{Al}$. During annealing step by step, the population of particles at the fibres did not change, but new $\left(\mathrm{Al}_{\mathrm{x}} \mathrm{Mg}_{1-\mathrm{x}}\right) \mathrm{Nd}$ cubic particles precipitate between 120 and $180{ }^{\circ} \mathrm{C}$ appeared. Above $180{ }^{\circ} \mathrm{C}$, the hexagonal $\beta$-phase and/or tetragonal $\mathrm{Mg}_{12} \mathrm{Nd}$ substitute the former cubic phase. Between 240 and $300^{\circ} \mathrm{C}$ the $\beta$-phase transforms into semicoherent tetragonal $\mathrm{Mg}_{12} \mathrm{Nd}$, too. Kiehn et al. [14] have estimated that ceramic fibres and the reaction products of the inorganic binder (containing $\mathrm{Al}_{2} \mathrm{O}_{3}$ ) in the preform enhanced the $\mathrm{Al}$ concentration due to decomposition in the QE22 matrix. Contrary to the unreinforced alloy, $\mathrm{Ag}$ remains dissolved in the matrix of the composite and does not take part in the precipitation process. The main weak pinning points seem to be the solute atoms or their small clusters.

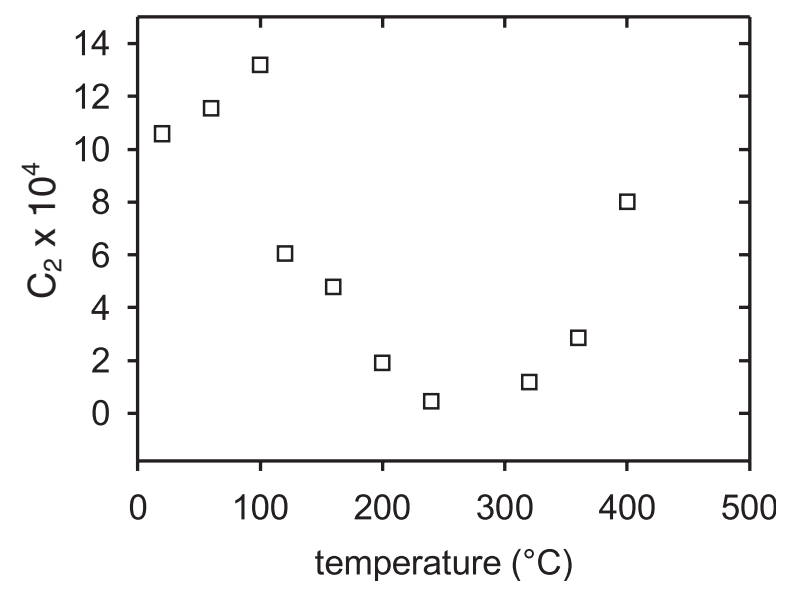

Fig. 2 Dependence of the $C_{2}$ parameter on upper temperature of thermal cycle. 
The obtained experimental data may be analysed using Eq (6) in the form $\delta=\delta_{0}+C_{1} \epsilon \exp \left(-C_{2} / \epsilon\right)$. The values of $C_{2}$ parameter are plotted against the temperature of thermal treatment in Fig. 2. The $C_{2}$ parameter is proportional $C_{2} \infty \ell^{-2 / 3}$ and, hence, the experimental results indicate that the mean distance between the weak pinning point increases with increasing temperature. This is reasonable because the dislocation density increases and the number of solute atoms (cluster) forming weak pinning points is constant. The $C_{2}$ parameter is practically constant at temperatures between 200 and $300{ }^{\circ} \mathrm{C}$ and then it slightly increases. This temperature variation of $C_{2}$ may be explained if the observations of Kiehn et al. [14] are taken into account. The plot of the $C_{1}$ parameter against the thermal treatment temperature is given in Fig. 3 .

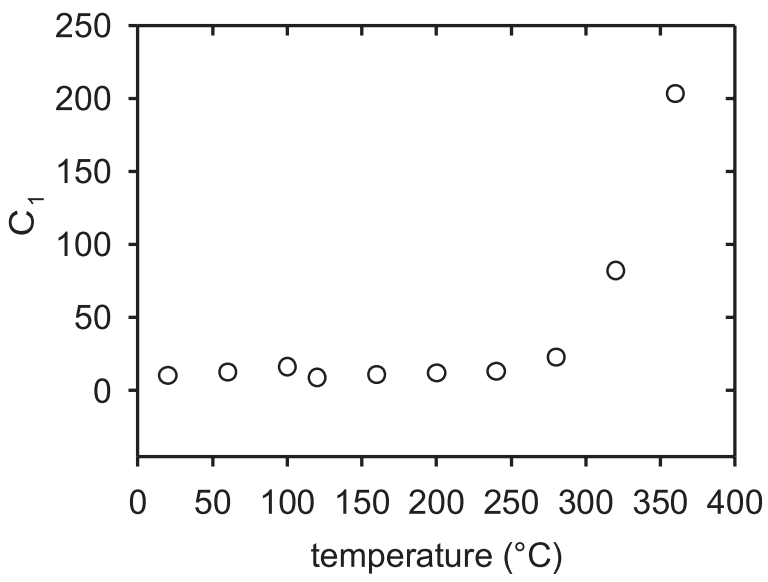

Fig. 3 Dependence of the $C_{1}$ parameter on upper temperature of thermal cycle.

The stress that is necessary for a thermal breakaway of dislocation loops $\sigma_{T}$ at a certain temperature is given by [13]

$$
\sigma_{T}=\sigma_{M}\left[1-\left(\frac{k T}{U_{1}} \ln A\right)\right],
$$

with

$$
A=\frac{2}{3} \frac{v}{\omega} \frac{\sigma_{M}}{\sigma_{0}}\left(\frac{k T}{U_{1}}\right)^{\frac{3}{2}}
$$

$\sigma_{M}$ is assumed to be the breakaway stress in the pure mechanical process. For a double loop with the loop length $\ell_{1}$ and $\ell_{2}$, the breakaway occurs under the stress

$$
\sigma_{M}=\frac{2 F_{m}}{b\left(\ell_{1}+\ell_{2}\right)} .
$$

Here $F_{m}$ is the maximum binding force between a dislocation and a pinning point. $U_{1}=4 / 3\left(F_{m}^{3} / \Phi\right)^{1 / 2}$, where $\Phi$ is a constant. All experiments were performed at ambient temperature; it is reasonable to consider that the influence of the thermal activation is, in the first approximation, the same. After thermal treatment, shorter dislocation segments (the mean distance between weak pinning points) become longer because of the enhanced dislocation density due to temperature cycling and due to the lower number of solute atoms. Then, the critical strain according to Eqs. (4) and
(9) that is indirect proportional to $\ell$ should decrease with increasing upper temperature of the cycle. It is observed experimentally (Fig. 1); the critical strain $\epsilon_{c r}$ decreases with increasing upper temperature of the cycle. This tendency is stopped at a temperature of $360{ }^{\circ} \mathrm{C}$ where the decrement component $\delta_{H}$ decreases. The critical strain becomes higher, which corresponds to the shorter dislocation loops. Thermal stresses produced near the matrix/ceramic fibre interfaces are accommodated by the formation of plastic zones. The dislocation density can increase only up to the moment when the plastic zones formed in the matrix begin to overlap. Consequently, the dislocation loops formed in the vicinity of the matrix/fibre interfaces have the opposite sign on the both sides of the fibre. It should be mentioned that the yield stress in the matrix at higher temperatures is lower than the internal stresses and, at temperatures higher than $360{ }^{\circ} \mathrm{C}$, the thermal tensile stresses change to compression ones.

\section{2 Mechanical cycling}

The logarithmic decrements measured for a sample without prior mechanical cycling and for a sample after 4320 cycles are plotted against the maximum strain $\epsilon$ of the bending amplitude in Fig. 4. It is evident that the values of the logarithmic decrement (at selected strain amplitudes) in the sample after 4320 cycles are lower than those for the samples without mechanical cycling. It can be seen that the strain amplitude dependence of the logarithmic decrement can be expressed as a sum of two components, the same as the equation (3), i.e.

$$
\delta=\delta_{0}+\delta_{H}(\epsilon)
$$

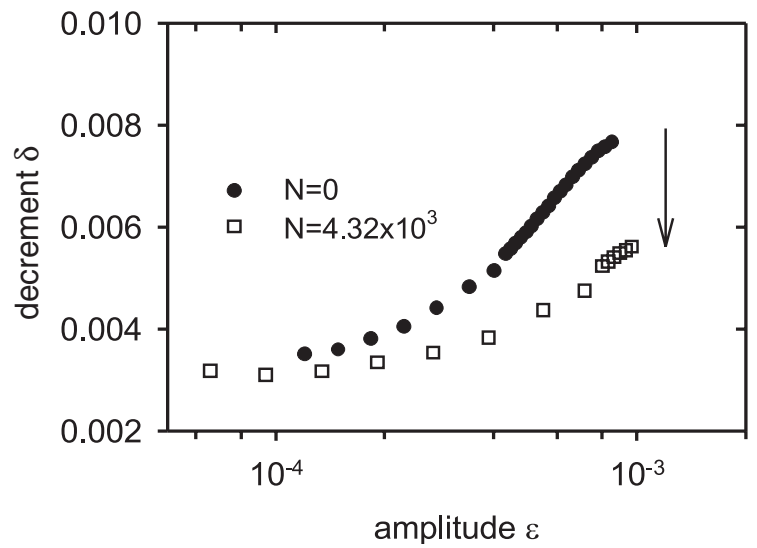

Fig. 4 Amplitude dependences of the logarithmic decrement for as received sample and after $4.32 \times 10^{3}$ cycles.

It is again assumed that dislocations are pinned by strong and weak pinning points. The mean distance between the strong pinning points is $L_{N}$ and the mean distance between two weak pinning points is $\ell$, with $\ell$ « $L_{N}$. It is also assumed that the mean total dislocation density is $\rho$ and that the periodic stress is applied. The logarithmic decrement in the strain amplitude independent region at low frequencies yields 


$$
\delta_{0}=\frac{\pi \omega B_{d}}{36 G b^{2}} \rho \ell^{4},
$$

where $B_{d}$ is the damping force per unit length of dislocation per unit velocity.

The stress (strain) dependence of the decrement component $\delta_{H}$ can be expressed by equation (6). The microstructure changes in the composite samples upon mechanical cyclic loading are primarily induced by plastic deformation in the matrix [15].

The logarithmic decrement estimated at the strain amplitude $\epsilon_{0}=1.3 \times 10^{-4}$ depends on the number of cycles as shown in Fig. 5. It can be seen that after a decrease in the logarithmic decrement at the onset of the cycling process, the decrement is more or less constant with some fluctuation between $10^{7}$ and $10^{8}$ cycles. Cycling for $N>10^{8}$ leads to an increase of the decrement (Fig. 5). The amplitude dependences of the logarithmic decrement component $\delta_{H}$ measured between $1.88 \times 10^{8}$ and $2.19 \times 10^{8}$ cycles

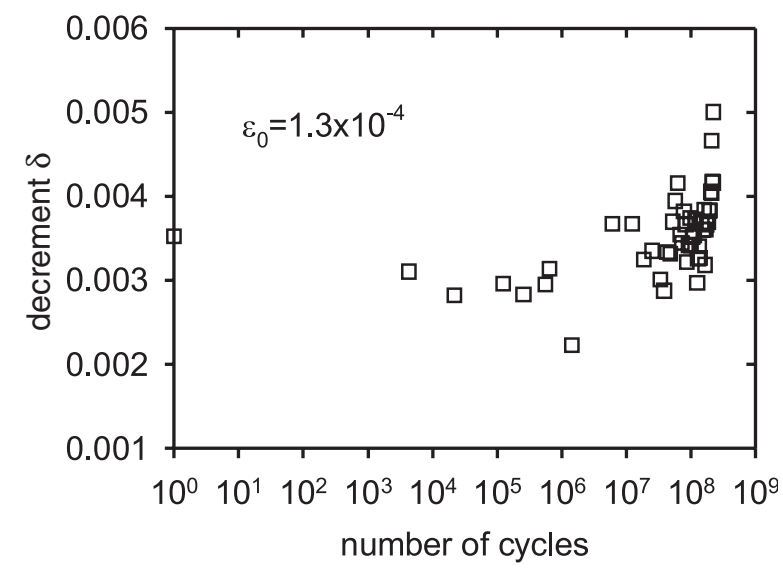

Fig. 5 Variation of the logarithmic decrement at $\epsilon_{0}=1.3 \times 10^{-4}$ with the number of cycles.

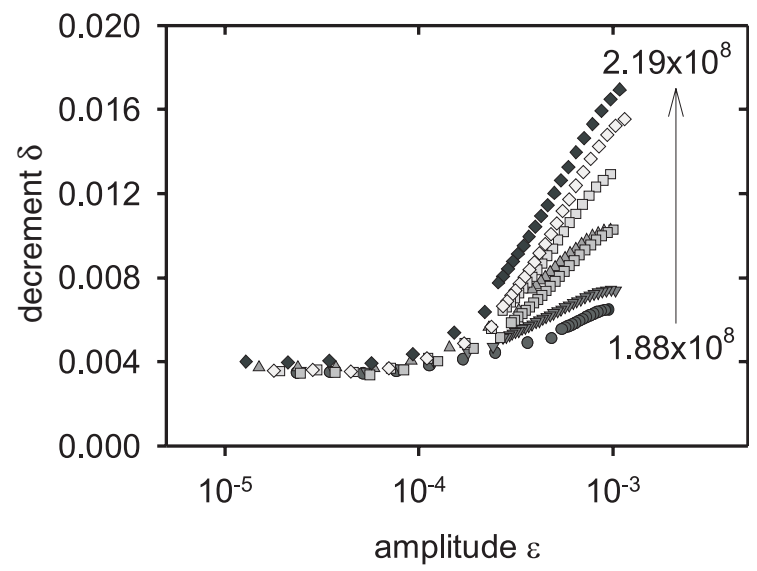

Fig. 6 Amplitude dependences of the logarithmic decrement for increasing number of cycles (at higher cycles). are shown in Fig. 6. It can be seen that the decrement significantly increases with increasing number of cycles in the amplitude dependent part. This indicates a rapid increase of the dislocation density and also an increase in the distance between the weak pinning points (shorter dislocation segments) in the matrix. This increase of the decrement, on the other hand, is accompanied by a decrease of the resonant frequency (see Fig. 7). The comparison of our results with a similar investigation of magnesium alloy

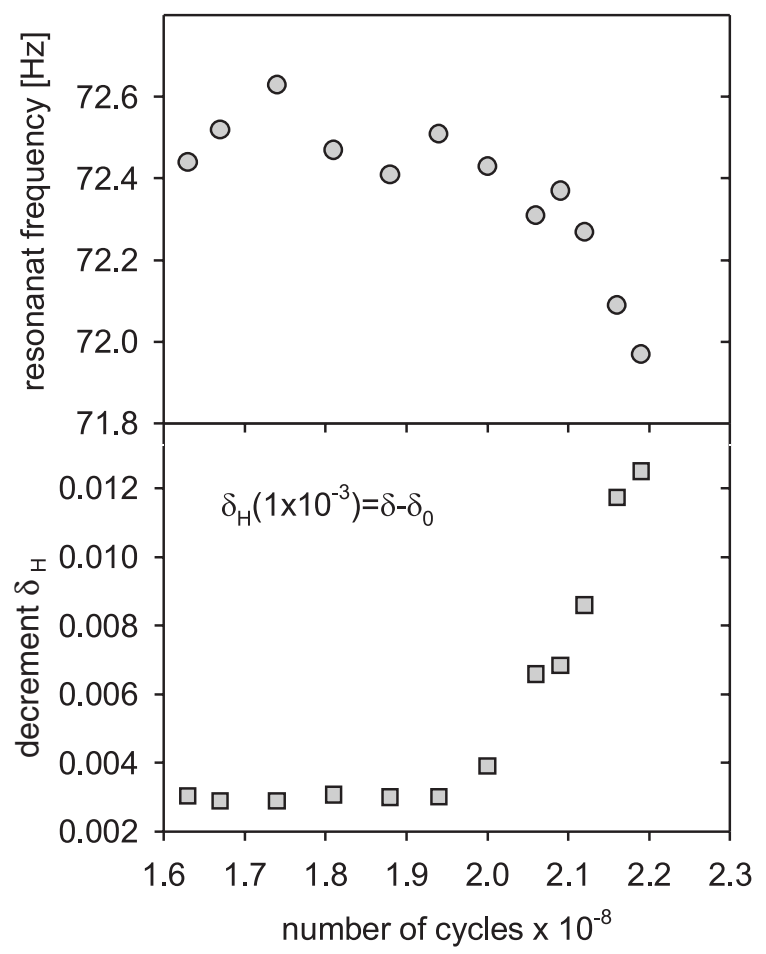

Fig. 7 Variation of the sample resonant frequency and decrement with the number of cycles. Decrement component $\delta_{H}$ is estimated at a maximum strain amplitude of $1 \times 10^{-3}$.

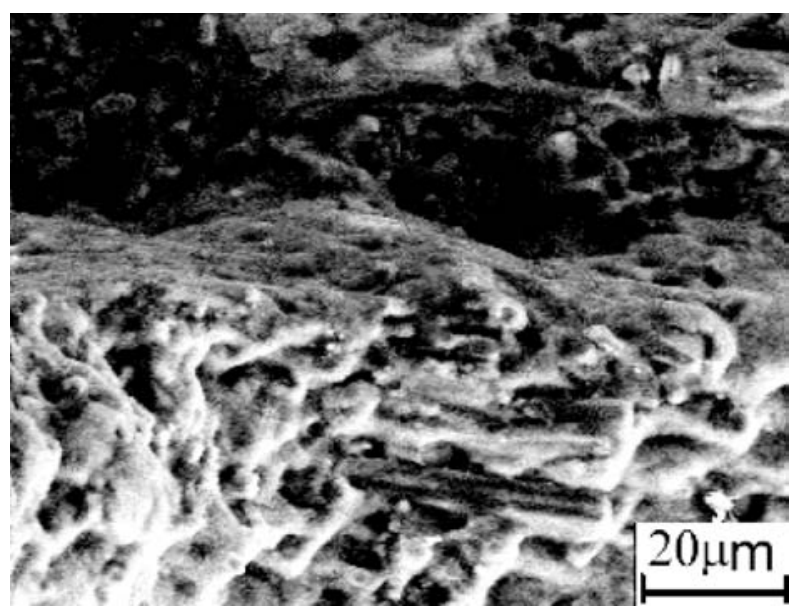

Fig. 8 Fibres pullout at the fracture surface. 
AZ91 reinforced with 15 vol.\% of short Saffil fibres [16] indicates that there is a substantial difference between the cycling loading behaviour of composites with AZ91 and QE22 matrix. While in the AZ91 composite cracks are formed during the cycling bending, such cracks were not observed in the composite with QE22 matrix [17]. We believe that this is due to the existence of the brittle intermetallic phase $\mathrm{Mg}_{17} \mathrm{Al}_{12}$ in the AZ91 alloy as well as in its composite. Small cracks are formed in this phase. Similar cracks were observed during thermal and mechanical loading of the AZ91 alloy $[8,16]$. The higher plasticity of the QE22 alloy without a brittle phase is very probably the reason for different fatigue behaviour of the $\mathrm{QE} 22 / \mathrm{Al}_{2} \mathrm{O}_{3}$ composite. Plastic deformation is accumulated in the matrix. The observed decrease of the damping at the onset of the cycling process (see Fig. 5) is very probably caused by a decrease of the mobile dislocation density. Dislocation segments are inactive due to dislocation-dislocation interaction. The measured decrease of the resonant frequency at the end of the fatigue process indicates a stiffness loss due to cracks and maybe also by an increase of the number of bowable or moveable dislocations as a function of cycling. A rapid increase in the amplitude dependent component of the decrement at the end of the sample life is due to rapid nucleation or growth of cracks and a resulting strong local increase in the free dislocation density. Newly created dislocations at cracks tips accommodate these stresses. The dislocations can be also absorbed by interfaces. Crack deflection along an interface is followed by the separation of the fibre/matrix interface. The pull out of fibres was observed at the fracture surface. Holes after fibres are visible in Fig. 8. No fibre fracture was observed.

\section{Conclusions}

The microstructure of $\mathrm{QE} 22 / \mathrm{Al}_{2} \mathrm{O}_{3}$ composites is stable up to $200{ }^{\circ} \mathrm{C}$. From the internal friction measurements, it can be concluded that changes in the microstructure occur at temperatures above about $200{ }^{\circ} \mathrm{C}$. These changes are very probably connected with migration of solute atoms and precipitation processes. The dislocation density slightly increases, which is very probably reflected by a small increase in the logarithmic decrement. Tensile internal stresses generated at temperatures higher than $220-240{ }^{\circ} \mathrm{C}$ are high enough to invoke motion of newly formed dislocations. Thermal cycling at temperatures higher than $\sim 360{ }^{\circ} \mathrm{C}$ causes a new situation: motion and annihilation of newly formed dislocations in the matrix under appearing compressive internal stresses leads to and the decrease of the decrement. And accumulation of the plastic deformation in the matrix presumably mainly due to crack nucleation or growth increased the amplitude independent as well as amplitude dependent components of the logarithmic decrement. Pull out of fibres during fracture of the composite was observed.

\section{Acknowledgement}

The work is part of the Research Project CZ-88/2006 (Scientific and Technical Co-operation between the Czech Republic and the Slovak Republic) financed by the Ministry of Education of the Czech Republic.

\section{References}

[1] SVOBODA, M., PAHUTOVÁ, M., MOLL, F., BŘEZINA, J., SKLENIČKA, V.: In: Magnesium Alloys and Their Applications. Ed.: Kainer, K.U. Weinheim, Wiley-VCH 2000, p. 234.

[2] POLMEAR, I. J.: Mater. Sci. Techn., 10, 1994, p. 1.

[3] KAINER, K. U.: In: Magnesium Alloys and Their Applications. Eds.: Mordike, B.L., Hehmann, F. Oberursel, DGM 1992, p. 415.

[4] OAKLEY, R., COCHRANE, R. F., STEVENS, R.: Key Engn. Mater., 104-107, 1995, p. 387.

[5] WILKS, T. E., KING, J. F.: In: Magnesium Alloys and Their Applications. Eds.: Mordike, B.L., Hehmann, F. Oberursel, DGM 1992, p. 431.

[6] KAINER, K. U.: Mater. Sci. Eng. A, 135, 1991, p. 243.

[7] GÖKEN, J., RIEHEMANN, W.: Mater. Sci. Eng. A, 324, 2002, p. 134.

[8] GÖKEN, J., RIEHEMANN, W.: Mater. Sci. Eng. A, 370, 2004, p. 417.

[9] ARSENAULT, J. R., SHI, N.: Mater. Sci. Eng., 81, 1986, p. 175.

[10] DUNAND, D. C., MORTENSEN, A.: Acta Metall. Mater., 39, 1991, p. 127.

[11] GRANATO, A. V., LUECKE, K.: J. Appl. Phys., 27, 1956, p. 583.

[12] DE BATIST, R.: In: Materials Science and Technology. Vol. 2B. Eds. Cahn, R.W., Haasen, P., Kramer, J. Weinheim, VCH 1994, p. 159.

[13] GRANATO, A. V., LUECKE, K.: J. Appl. Phys., 52, 1981, p. 7136.

[14] KIEHN, J., SMOLA, B., VOSTRÝ, P., STULÍKOVÁ, I., KAINER, K. U.: phys. stat. sol. (a), 164, 1997, p. 709.

[15] LLORCA, J.: Progr. Mater. Sci., 47, 2002, p. 283.

[16] TROJANOVÁ, Z., MIELCZAREK, A., RIEHEMANN, W., LUKÁČ, P.: Comp. Sci. Tech., 66, 2006, p. 585

[17] MIELCZAREK, A., RIEHEMANN, W., TROJANOVÁ, Z., LUKÁČ, P.: Mater. Sci. Eng. A, In press. 